\title{
Montmorillonite KSF Clay as Novel and Recyclable Heterogeneous Catalyst for the Microwave Mediated Synthesis of Indan-1,3-Diones
}

\author{
Omid Mavi' and Masoud Giahi ${ }^{*}$

\begin{abstract}
Department of Chemistry, Pavame Noor Cniversin (PNU), Roodsar, Guilan. Iran. "E-mail: omid_manviâpnuacim -Department of Chemistry: Factuty of Sciences, Islamic Azad Lniversity, Lahijan Branch, Lahijan, Iran Received Julv 20, 2009, Accepted October 2, 2009
\end{abstract}

\begin{abstract}
Various indan-1,3-dione derivatives were synthesized from the reaction of different phthalic anhydrides with diethylmalonate using montmorillonite KSF clay as a recyclable heterogeneous acidic cataly st and microwave irradiation in good yields and short reaction times.
\end{abstract}

Key Words: Montmorillonite KSF clay, Phthalic anhydrides, Indan-1.3-diones. Microwave irradiation

\section{Introduction}

Development of the simple. efficient and general sy'nthetic methods for widely used organic compounds from readily available reagent is one of the major challenges in organic synthesis. For many years. the $\beta$-dicarbonyl compounds have been studied intensively owing to their synthetic and biological significance. Theoretical aspects and physicochemical properties of $\beta$-dicarbonyl compounds were studied systematically by Perjéssy and coworkers. ${ }^{1}$ The most known methods for preparation of the $\beta$ dicarbonyl compounds are rearrangements of the phthalides or condensation of indan-1.3-diones with carbonyl compounds. ${ }^{\text {?a }}$ Well known indan-1,3-dione derivatives are important as anticoagulant drugs or rodenticides. ${ }^{-\mathrm{b}}$ In addition to anticoagulant effect and rodenticidal activity, these compounds have shown parasiticidal effects, ${ }^{\text {¿c }}$ analgestic. ${ }^{2 \mathrm{a}}$ antibacterial, ${ }^{\text {¿e }}$ hypermetabolic. ${ }^{\text {if }}$ and bronchodilator activities. . $^{\text {? }}$

Various sy nthetic approaches to the indan-1.3-dione derivatives have been developed. ${ }^{3-6}$ Although some of them are convenient protocols for certain synthetic applications. the majority of them suffer from at least one disadvantage. such as strongly acid conditions. long reaction time high temperature poor selectivity. expensive reagent. toxicity. and need for excessive amounts of reagents.

Consequently. it is desirable to develop an easty manipulative procedure. as well as to avoid using strong acids or bases and other corrosive media and replacing hazardous or expensive reactants and reagents by safer and economical ones. In achieving many of these goals. catalysts help the sy nthetic chemist in a big way. Catalysts are capable of making impracticable reactions to occur under the mildest possible conditions.

In recent years. the use of solid acidic cataly'sts such as different clays has received considerable attention in different areas of organic synthesis because of their environmental compatibility, reusability. high selectivity, operational simplicity. noncorrosiveness. low cost and ease of isolation of the products. In particular. clay catalysts make reaction processes convenient. more economic, and envirommentally benign and act as both Bronsted and Lewis acids in their natural and ion-exchanged forms, enabling them to function as efficient catalysts for various organic transformations. ${ }^{8}$ - $-\mathrm{f}$
Recently, montmorillonite KSF clay has been employed for esterification of mandelic acid catalyzed by heteropoly acid. ${ }^{8 g} \mathrm{Fe}$ $(\mathrm{Cp})_{2} \mathrm{PF}_{6}$ catalyzed Strecker reactions of ketones and aldehy'des under solvent-free conditions. ${ }^{8 h}$ selective toluene methylation over chromia pillared montmorillonites. ${ }^{8 i}$ synthetic developments in a powerful inino Diels-Alder reaction (Povarov reaction).$^{8}$ rhodium(III) iodide hydrate catalyzed three-component coupling reaction (synthesis of $\alpha$-aminonitriles from aldehydes), ${ }^{8 k}$ synthesis of mono- and di- $\beta$-hydroxy - $\beta$-bis(trifluoromethyl)-(di)imines. ${ }^{8}$ and voltammetric determination of analgesics using a montmorillonite modified electrode. ${ }^{8 \mathrm{~m}}$

In addition, a growing interest has been shown in the use of microwave irradiation in organic șythesis in the last few years. Microwave-mediated solvent-free sy nthesis offers advantages for reducing hazardous explosions and the removal of high boiling solvents from the reaction nuxtures. ${ }^{9.11}$

\section{Results and Discussion}

In continuation of our studies about nicrowave-assisted reactions on solid surfaces under the solvent free conditions. ${ }^{12}$ herein it is described a fast, convenient and simple method for the synthesis of $\beta$-dicarbonyl compounds (indan-1.3-dione derivatives) from the reaction of different phthalic anhydrides with diethylmalonate using montmorillonite KSF clay as an efficient

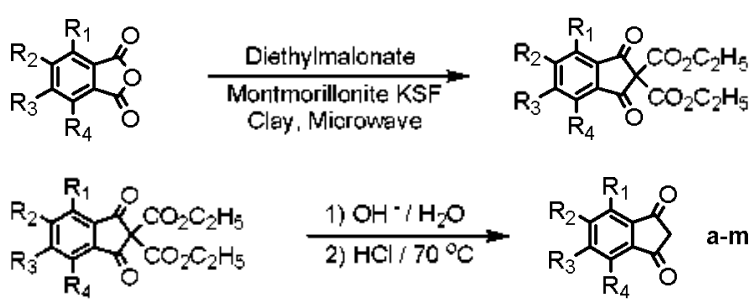

h) $R_{1}=F_{;} R_{2}=R_{3}=R_{4}=H$

i) $R_{1}=R_{2}=R_{3}=R_{4}=C l$

j) $\mathbf{R}_{2}=\mathbf{R}_{3}=\mathrm{CH}_{3} ; \mathbf{R}_{1}=\mathbf{R}_{4}=\mathrm{H}$

k) $\mathbf{R}_{1}=\mathbf{R}_{3}=\mathrm{CH}_{3} ; \mathbf{R}_{2}=\mathrm{R}_{4}=\mathrm{H}$

l) $\mathrm{R}_{1}=\mathbf{R}_{4}=\mathrm{CH}_{3} ; \mathbf{R}_{2}=\mathrm{R}_{3}=\mathrm{H}$

m) $R_{1}=C_{2} H_{5} ; R_{2}=R_{3}=R_{4}=H$

e) $R_{1}=O C_{2} H_{5} ; R_{2}=R_{3}=R_{4}=H$

f) $R_{1}=B r ; R_{2}=R_{3}=R_{4}=H$

g) $R_{2}=B r_{1} R_{1}=R_{3}=R_{4}=H$

Scheme 1. Microwave-mediated solvent-free synthesis of indane-1,3dione derivatives on montmorillonite KSF clay. 
Table 1. The yields and reaction times for the microwave-induced synthesis of compounds a-m on clay KSF.

\begin{tabular}{|c|c|c|c|c|c|}
\hline \multirow[b]{2}{*}{ Entry } & \multirow[b]{2}{*}{ Product } & \multirow{2}{*}{$\begin{array}{c}\mathrm{Mp}{ }^{\circ \mathrm{C}} \\
\text { (Lit. } \mathrm{Mp} \text { "C) }\end{array}$} & \multirow{2}{*}{$\begin{array}{c}\text { Reaction } \\
\text { time } \\
\text { (mini) }\end{array}$} & \multicolumn{2}{|c|}{ Yield $(\%)^{b}$} \\
\hline & & & & $\begin{array}{l}\text { Fresh } \\
\text { Clay }\end{array}$ & $\begin{array}{c}\text { Recovered } \\
\text { Clay }\end{array}$ \\
\hline l & & $\begin{array}{c}128 \sim 131 \\
(129 \sim 132)\end{array}$ & 7.5 & 87 & 79 \\
\hline 2 & & $\begin{array}{c}124 \sim 126 \\
(125 \sim 128)\end{array}$ & 9.5 & 74 & 65 \\
\hline 3 & & $\begin{array}{l}116 \sim 118 \\
(114 \sim 116)\end{array}$ & 9 & 76 & 67 \\
\hline 4 & & $\begin{array}{c}141 \sim 143 \\
(145 \sim 147)\end{array}$ & 11 & 68 & 60 \\
\hline 5 & & $\begin{array}{c}115-117 \\
(111)\end{array}$ & 11.5 & 62 & 54 \\
\hline 6 & & $\begin{array}{c}125-129 \\
(\mathrm{dec}) \\
(>120 \mathrm{dec})\end{array}$ & 8.5 & 79 & 71 \\
\hline 7 & & $\begin{array}{l}148 \sim 151 \\
(152 \sim 153)\end{array}$ & 8 & 82 & 74 \\
\hline 8 & & $\begin{array}{c}114 \sim 117 \\
(117 \sim 118)\end{array}$ & 7.5 & 85 & 77 \\
\hline 9 & & $\begin{array}{c}>135(\mathrm{dec}) \\
(\mathrm{dec})\end{array}$ & 10.5 & 71 & 62 \\
\hline 10 & & $\begin{array}{c}154-157 \\
(159)\end{array}$ & 11 & 68 & 57 \\
\hline 11 & & $\begin{array}{c}139-142 \\
(137-138)\end{array}$ & 12 & 65 & 56 \\
\hline 12 & & $\begin{array}{c}183 \sim 185 \\
(187-188)\end{array}$ & 11.5 & 66 & 54 \\
\hline 13 & & $\begin{array}{c}145-149 \\
(148)\end{array}$ & 11 & 68 & 55 \\
\hline
\end{tabular}

$\overline{\text { All isolated products are known and their spectra and plysical data have }}$ been reported in the literature. "Isolated vields after recrystallization. The applied KSF clay in the first cycle. was tiltered off. washed with methanol (2 $25 \mathrm{~mL}$ ) and dried at $120{ }^{\circ} \mathrm{C}$ for 5 h under the reduced pressure to be reused in the subsequent reactions which showed the gradual decrease in activity, a) Indan-1,3-dione b) 4-Methyl-indan-1,3-dione, c) 5-Methylindan-1.3-dione d) 4-Methoxv-indan-1.3-dione e) 4-Ethoxy-indan-1.3dione. f) 4-Bromo-indan-1.3-dione. g) 5-Bromo-indan-1.3-dione. h) 4Fluoro-indan-1,3-dione. i) 4,5,6.7-Tetrachloro-indan-1,3-dione. j) 5,6Dimethy-indan-1,3-dione. k) 4.6-Dimethy-indan-1.3-dione. I) 4.7-Dimethyl-indan-1,3-dione m) 4-Etlyl-indan-1.3-dione.

heterogeneous catalyst and microwave irradiation in two steps (first formation of a diketodiester and second the subsequent hydrolysis and decarbosylation of a diketodiester to produce indau 1.3-dione derivatives) (Scheme 1). All the infornation was tabulated in Table 1. It is notable that all attempts to prepare the diketodiester in the absence of the KSF clay failed which shows its role as an acid catalyst.

\section{Experimental Section}

Chenicals were purchased from Aldrich and Merck chemical companies and used without further purification. The composition of the applied montmorillonite KSF clay (purchased from Fluka) is $53.2 \% \mathrm{SiO}_{2} .18 .8 \% \mathrm{Al}_{2} \mathrm{O}_{3}, 5.1 \% \mathrm{Fe}_{2} \mathrm{O}_{3}, 2.9 \% \mathrm{CaO}$, $2.8 \% \mathrm{MgO} .6 \% \mathrm{H}_{2} \mathrm{SO}_{4}$, specific gravity of $2.4 \sim 2.5$, bulk density of 800 to $850 \mathrm{~g} / \mathrm{L}$ and $8.1 \%$ loss on ignition. surface area of 20 to $40 \mathrm{~m}^{2} / \mathrm{g}$ and $\mathrm{pH}$ value of 2.1 (pH is measured on $25 \mathrm{~mL}$ distilled water into which 2 grams of the clay powder is dispersed). ${ }^{13,14}$

Melting points were measured on an Electro thermal 9100 apparatus. The ${ }^{1} \mathrm{H} N \mathrm{NR}$ and ${ }^{13} \mathrm{C}$ NMR spectra were recorded on FT-NMR JEOL FX 90Q spectrometer using TMS as internal standard $(\delta / \mathrm{ppm})$. The relevant products were characterized by comparison of their spectral and physical data with the authentic samples.

In a typical experiment. 4-bromophthalic anlydride $(0.470 \mathrm{~g}$. 2 mmole), diethylmalonate $(0.360 \mathrm{~g} .2 .2 \mathrm{mmole})$ and montmorillonite KSF clay ( $(1.0 \mathrm{~g})$ mixed and placed in a quartz tube, and introduced into a Synthewave 402 (Prolabo. France) single mode focused microwave reactor for $8 \mathrm{~min}$ at $130^{\circ} \mathrm{C}$ (monitored temperature $)^{15}$ with continuous rotation. The reaction mixture was then allowed to cool to room temperature and the resulting product extracted into diclloromethane $(2 \times 25 \mathrm{~mL})$. The montmorillonite KSF clay was filtered off and the solvent removed by rotary evaporation. The red solid precipitate (diketodiester) was washed with distilled water, dissolved in $8 \% \mathrm{NaOH}(30 \mathrm{~mL}$. $2 \mathrm{~min})$ and filtered. The filtrate was acidified with a hot solution $\left(70-80^{\circ} \mathrm{C}\right)$ of conc. $\mathrm{HCl}(15 \mathrm{~nL})$ in water $(75 \mathrm{~mL})$ and the product kept at about $70^{\circ} \mathrm{C}$ until the decarboxylation ceased ( 10 min). Finally. the obtained solid filtered, dried in the oven and recrystallized twice from acetone (distilled benzene was used for other products) to get 5-bromo-indan-1.3-dione (g) as a red solid; $\mathrm{np} 148 \sim 151^{\circ} \mathrm{C}$, yields $0.368 \mathrm{~g} .82 \%$ with the fresh KSF clay and 0.334 g. $74 \%$ with the recovered KSF clay. (lit. mp $152 \sim 153^{\circ} \mathrm{C}$, reaction time for formation of the diketodiester $24 \mathrm{~h}$ using acetic anhydride, ethyl acetoacetate and triethylanuine). ${ }^{3} \hat{o}_{\mathrm{H}}\left(90 \mathrm{MHz}, \mathrm{CDCl}_{2}\right) 3.79$ (s. $\left.2 \mathrm{H} . \mathrm{CH}_{2}\right) .7 .72-8.16(\mathrm{~m}$, 3H. Ar). o. (22.5 MHz. $\left.\mathrm{CDCl}_{3}\right)$ 51.8. 127.1. 130.4, 131.9. 136.5 . 139.3. 196.5.

Results summarized in the Table 1 indicate the scope and generality of the reaction with respect to the various phthalic anlydrides. The nature of the substituents on the aromatic ring of phthalic anhydride has different influences. It is of interest to note that the presence of the electron withdrawing groups such as cllorine and fluorine which increase the polarity of the carbonyl group inductively' give high yields of products as well as the short reaction time compared to the electron donating groups like methyl, ethyl, methoxy and ethoxy.

Using of the solid acid catalyst in this method offers high yields of products compared to the conventional procedures, probably due to the more molecular interactions. 


\section{Conclusion}

In summary. we have described a new. simple. easy and highly efficient procedure for the synthesis of $\beta$-dicarbonyl compounds using environmentally acceptable montmorillonite KSF clay. The catalyst is inexpensive. non-toxic and reusable which makes the process convenient. more economic and benign. The recyclability detail of the KSF clay. which is another advantage of our method, has been explained in caption of the Table 1 and the relevant data is tabulated.

Acknow ledgments. Financial support from the Payame Noor University (PNU). Roodsar. Iran is gratefully appreciated.

\section{References}

1. (a) Perjéssy, A.; Hnùiar, P. Spectrochim. Acta 1982, A 38,499. (b) Boháx. A.; Perjessy, A.; Loos, D.; Hruciar, P. Monatsch. Chem. $1991,122,943$.

2. (a) Perjéssy, A.; Toma, S. Acta Fac. Renm Natum Lniv. Comenianae. Chimia 1983, 31, 1. (b) Soulier, . . P.: Guegen. T. Rev Hemat. 1948. 3. 180. (c) Hazleton, L. W.: Dolben. W. H. US. Pat. 2884357, 1959. (d) Kubovic, M: Prazic, M.: Atanackovic, D. Proc Soc. Exp. Biol. Afed. 1955, 90, 660. (e) Thrombosis, G. E.: Embolism, I. International Conf. Basel 1954, 271. (f) Soderberg. U.; Wachtmeister, C. A. Phamacol J. Exp. Therap 1956, 117,298 (g) Blumberg, H.; Davton, H. B.: Gordon, S. M. Science 1958, I27, 188.

3. (a) Buckle, D. R.; Smith, H. US. Pat. 3936504, 1976. (b) Rajur, R.; Rao, V. N.; Kim, H.-O.; Nagafuli, P.: Heanult, X.; Williams, I. D.; Peet, N. P. Smth Commm 2009, 39, 626. (c) Kuck, D: Hackfort, T.: Nemmann, B.: Stammler, H.-G. Polish J. Chem. 2007, 81,875 .

4. (a) Kim E. T.; An, K. M.; Ko, S. Y. Bull. Korean Chem. Soc, 2006 , 27,2019. (b) Abou Elnaaty, T. M. Smth Commm. 2006, 36,2281. (c) Mosher, W. A.: Soeder, R. W.J. Ong Chem. 1971,36, 1561 .

5. (a) Shapiro, S. L.; Geiger, K: Freedman, L. J. Org. Chem. 1960 , 25, 1860. (b) Matano, Y.: Imahori, H. J. Org. Chem. 2004, 69, 5505. (c) Wu, D.: Ren, Z; Cao, W: Tong, W. Smh. Commul. $2005,35,3157$.

6. (a) Pawar, G. G.; Bineesh, P.; Kumar, P. S. R.; Rangnekar, D. W: Kanetkar, V. R. Asion J. Chem 2005, 17, 1097. (b) Sanguinet, L.; Williams, J. C.; Yang, Z.; Twieg, R. T.: Mao, G.; Singer, K. D.: Wiggers, G.: Petschek, R. G. Chem Mater. 2006, 18, 4259. (c) Ren, Z; Cao, W.; Tong, W; Chen, J; Deng, H.; Wu, D. Swth.
Commm. 2008, 38, 2200

7. (a) Comelis, A.; Laszlo, P. Sinlet 1994, 155, (b) Sen, S. E.: Smith, S. M.: Sullivan. K. A. Tetrahedron 1999. 55, 12657.

8. (a) Li, T. S.; Jin, T. S. Chinese J. Org. Chem. 1996, 16, 385. (b) Balogh, M.; Laszlo, P. Onganic Chentistry Ling Clay, SpingerVerlag: New York, 1993 (c) Laszlo, P. Science 1987, 235, 1473. (d) Laszlo. P. Pure Appl Chem 1990, 62,2027. (e) Reddy, G. I.: Latha, D; Thirupathaiah, C; Srinivasa, R. K. Tetrahedron Lett. 2005, 46, 301. (f) Yadav, J. S.; Reddy, B. V. S.; Suritha, V.; Reddy, K. S.: Ramakrishna, K. V. S. Tetwahedron Lett. 2004, $42,7947$. (g) Rafiee, E.; Toshaghani, M.: Tork, F.: Fakhri, A.: Eavani, S. J. Hol. Catal. A. Chem. 2008, 283, l, (h) Khan, N. U. H.; Agrawal, S.; Kureshy, R. I.; Abdi, S. H. R.; Singh, S.; Suresh, E.: Tasra, R. V. Tetrahedron Lett. 2008, 49, 640) (i) Binitha, N. N.; Sugunan, S. Catal. Conmm 2008, 9.2376. (j) Kouznetsov, V. V. Tetrahedron 2009, 65, 2721. (k) Maihi, A.: Kim, S. S.; Kadam, S. T. Tetrahedron 2008, 64, 5509. (1) Marquet, N.; Grunova, E.; Kirillov, E: Bouyahyi, M.; Thomas, C. M.; Carpentier, J. F. Tetrahedron 2008, 64.75. (m) Muralidharan, B.: Gopu, G.; Vedhi, C.: Manisankar, P. Appl Clay Sci 2008, 12, 206.

9. (a) Lauren, R.; Leporterie, A.; Dubac, T.; Berlan, J.; Lauverie, S.; Audhuy F. M. J. Org. Chent 1992, 57, 7099 (b) Caddick, S. Tetrahedron 1995, 51, 10403. (c) Lidstrom, P.: Tiemey, T.: Wathey, B.; Westman, J. Tetrahedron 2001, 57,9225 (d) Bose, A. K.: Manhas, M. S.; Ganguly, S. N.; Shamna, A. H.; Banik, B. K. Sinthesis 2002, 1578 . (e) Loupy, A.; Petit, A.; Hamelin, ..; Texier-Boullet, F.; Jacquault, P.; Mathe, D. Sinthesis 1998, 1213.

10. (a) Vanma, R. S. Green Chem 1999, 1,43 (b) Loupy, A. Wicrowaves in Organic Sinthesis; Wiley-VCH: Weinheim, 2002 (c) Kappe, C. O.; Stadler, A. Hicroweres in Organic and Hedicinal Chemistry, Wiley-VCH: Weinheim, 2005. (d) Tierney, J. P.; Lidstrom, P. Aiciowave Assisted Organic Sinthesis: Blachwell: Oxford 2005

11. (a) Vama, R. S. Clean Prod. Pros. 1999, 1, 132. (b) Bram, G.; Loupy, A.; Villemerin. D. Solid Suppont and Catalyzed in Organic Chemistry; Ellis Horwood: London, 1992 (c) Borlah, A.: Barlah. M.; Prajapti, D.; Sandhu, J. S. Chem. Lett. 1996, 965.

12. (a) Habibi, D. Marvi, O. Can. J. Chem. 2007, 85, 81 (b) Habibi, D.: Marvi, O. Catal. Contmun 2007, 8, 127. (c) Habibi, D.; Marvi, O. Akivo 2006, xiii, 8. (d) Habibi, D; Marvi, O.J. Serb. Chem. Soc. 2005, 70,579. (e) Habibi, D.; Marvi, O. Sinth Commm. 2007, 37, 3165. (f) Habibi, D.: Marvi, O. Chinese J. Chem. 2008, 26, 522.

13. Alas, M.; Gubelmann, M:- Popa, J. M. US. Pat. 6018057, 2000.

14. Woods, H. T. US. Pat. 4042633, 1977.

15. (a) Commannot, R.: Didenot, R.: Gardais, I. F. Rhone-Poulenc/ Prolabo, Paent 8403 396, 27 Oct., 1986. (b) Prolabo, Fr., Patent $62241 / \mathrm{D}, 14669 \mathrm{Fr}, 23 \mathrm{Dec} ., 1991$. 